Conf-940865--4

The subrritted manuscript has been authored by a controctor of the U.S. Government under contrect No. DEACO5-84OR2 1400. Accordingly, the U.S. Government retans a nonexchusive. royalty-free license to publish or reproduce the published form of this contribution. or allow others to do so, for U.S. Government purposes."

\title{
EVOLUTION OF OXIDATION AND CREEP DAMAGE MECHANISMS IN HIPed SILICON NITRIDE MATERIALS ${ }^{\dagger}$
}

\author{
Andrew A. Wereszczak, Mattison K. Ferber, Timothy P. Kirkland, and \\ Karren L. More \\ High Temperature Materials Laboratory \\ Oak Ridge National Laboratory \\ P. O. Box 2008, Bldg. 4515, MS 6064 \\ Oak Ridge, TN 37831-6064
}

\begin{abstract}
Several yttria-fluxed, hot-isostatically pressed (HIPed) silicon nitrides have been tensile creep tested at temperatures representative of those present in expected gas turbine engines. Creep and oxidation assisted damage mechanisms concurrently evolve when these materials are tested at relatively high temperatures and low stresses (i.e., long exposure times at temperature). Atmospheric creep testing results in the creation of oxygen and yttrium gradients across the radial dimension of the specimens. High concentrations of oxygen and yttrium coincide with dense populations of lenticular-shaped cavities near the surface of the crept specimens. The center of the tensile specimens was devoid of oxygen or yttrium; in addition, lenticular cavities were rarely observed. The gradient in lenticular-cavity concentration is coincident with the oxygen and yttrium gradients. Stress corrosion cracking (SCC) also occurs in these HIPed silicon nitrides when they are subjected to stress at high temperatures in ambient air. The size of this damage zone increases when the temperature is higher and/or the applied stress is lower. Stress-corrosion cracking initiates at the surface of the tensile specimen and advances radially inwards. What nucleates SCC has not yet been identified, but it is believed to result from a stress-concentrator (e.g., machining damage) at the specimen's surface and its growth is a result of the coalescence of microcracks and cavities. The higher concentration of oxygen and yttrium in the grain boundaries near the specimen's surface lessens the local high temperature mechanical integrity; this is believed to be associated with the growth of the SCC zone. This SCC zone continues to grow in size during tensile loading until it reaches a critical size which causes fracture.

$\dagger$ Research sponsored by the Department of Energy, Assistant Secretary for Energy Efficiency and Renewable Energy, Office of Transportation Technologies, as part of the Ceramic Technology Project of the Materials Development Program, under contract DE-AC05-84OR21400 managed by Martin Marietta Energy Systems, Inc.




\section{DISCLAIMER}

This report was prepared as an account of work sponsored by an agency of the United States Government. Neither the United States Government nor any agency thereof, nor any of their employees, make any warranty, express or implied, or assumes any legal liability or responsibility for the accuracy, completeness, or usefulness of any information, apparatus, product, or process disclosed, or represents that its use would not infringe privately owned rights. Reference herein to any specific commercial product, process, or service by trade name, trademark, manufacturer, or otherwise does not necessarily constitute or imply its endorsement, recommendation, or favoring by the United States Government or any agency thereof. The views and opinions of authors expressed herein do not necessarily state or reflect those of the United States Government or any agency thereof. 


\section{DISCLAIMER}

Portions of this document may be illegible in electronic image products. Images are produced from the best available original document. 


\section{INTRODUCTION}

Hot isostatically pressed (HIPed) silicon nitride is a candidate structural ceramic for advanced gas turbine (AGT) engine components, e.g., stators, shrouds, and rotors. HIPed silicon nitride is of interest as a material because it has an inherently higher operating temperature capability over that of conventional metallic alloys. This greater operating temperature allows AGT engine efficiency to increase while increasing the performance. To take advantage of this, the chosen material must maintain the close tolerances (when subjected to temperature and stress) associated with the various components in an AGT engine so that dimensional stability is retained over long component lifetimes.

However, damage evolves in HIPed silicon nitride when it is subjected to the temperatures and stresses that are representative of AGT engine components. The accumulation of damage affects both the mechanical integrity of the material and the dimensional stability of the component. Both oxidation and the application of a stress are driving forces that initiate and enhance the activity of damage mechanisms (e.g., cavitation, stress corrosion cracking) in yttria-fluxed, HIPed silicon nitride at elevated temperatures. It should be noted here we will frequently refer to oxidation as the transport of oxygen into the yttrium-silicon oxynitride grain boundary phase and its effects, and not the passive deposition of a silica layer on the silicon nitride specimen surface. The transport of oxygen into the grain boundary phase is a kinetic process whose extent is a function of the amount and type of sintering aid, grain boundary crystallinity, and the impurity content within the grain boundaries.

The effects from oxidation and creep in a HIPed silicon nitride (PY6, GTE Laboratories, Waltham, MA) have been uncoupled. ${ }^{1}$ A series of flexural dynamic fatigue tests was conducted in ambient air and inert environments at $1370^{\circ} \mathrm{C}$. The results of that study are illustrated in Fig. 1. The flexure strength was found to be independent of the stressing rate at $1370^{\circ} \mathrm{C}$ in inert environments, even though evidence of creep was present in specimens tested at the slower stressing rates. The intriguing contradiction of this study was that the flexure strengths of specimens tested in ambient air continually decreased as the stressing rate was slower. Specimens tested in both ambient air and inert environments crept at the slower stressing rates; however, it was the initiation of stress corrosion cracking (as evidenced by

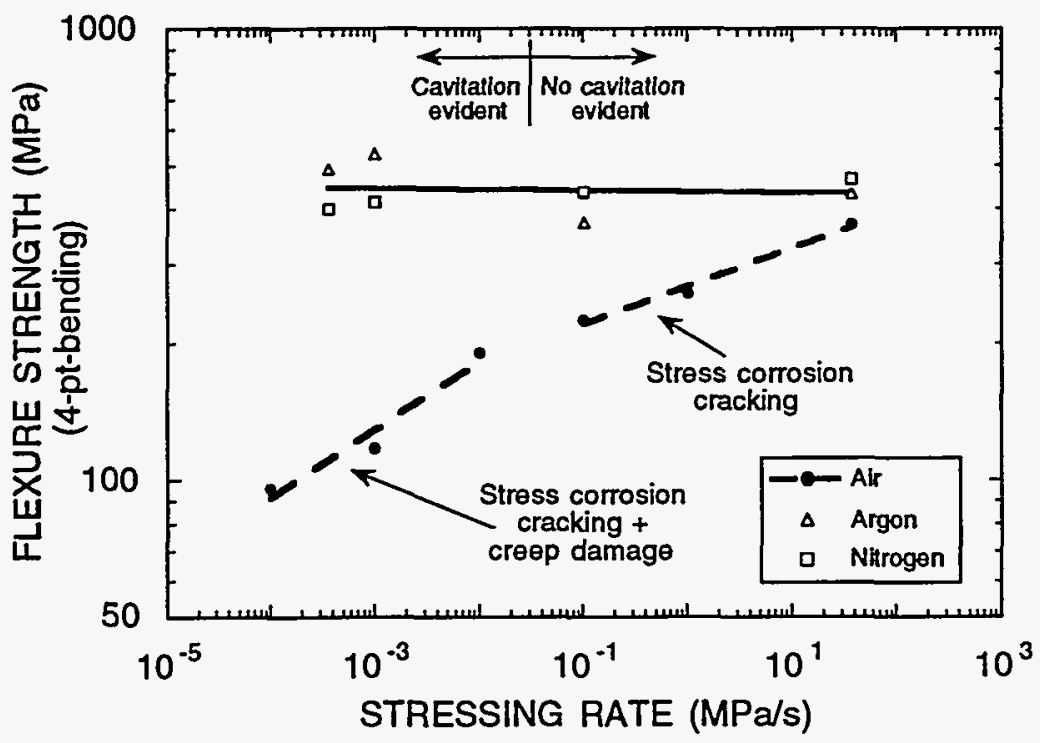

Figure 1. Dynamic fatigue results showed that the flexure strength of HIPed silicon nitride (PY6) was independent and dependent of the stressing rate in inert and ambient air environments, respectively. ${ }^{1}$ 
the presence of a macroscopically large damage zone) in specimens tested in air that reduced the flexure strengths. This previous study yielded evidence that oxidation and creep damage may be mutually enhanced by one another. We have been further examining effects associated with oxidation and creep damage and this article reports more recently obtained important information.

\section{EXPERIMENT}

Several commercially available HIPed silicon nitrides have been tested (NCX-5102, NT154, and NT164, all manufactured by Saint Gobain/Norton Industrial Ceramics Corporation, Northboro, MA, and PY6, manufactured by GTE Laboratories Inc., Waltham, MA) and have several characteristics in common. The microstructures of these silicon nitrides typically have acicular grains $(\approx 1$ to $6 \mu \mathrm{m}$ long) mixed with equiaxed grains $(\approx 0.1$ to $1 \mu \mathrm{m})$. The silicon nitrides described in the present study contain various amounts (4-6\%) of yttrium oxide $\left(\mathrm{Y}_{2} \mathrm{O}_{3}\right)$ as a sintering aid or flux. Due to the small concentration of flux material, the grain boundary thicknesses typically are on the order of only a nanometer.

The HIPed silicon nitride materials were machined into button-head geometries (gage dimensions $=35 \mathrm{~mm}$ length and 6.00 or $6.35 \mathrm{~mm}$ diameter) for tensile creep testing. Specimens were loaded in tension in ambient air using a screw-driven testing machine equipped with an analog, electronic closed-loop, load controller. A short, two zone furnace (50 mm hot zone) capable of achieving $1500^{\circ} \mathrm{C}$ was used. Contact extensometers were used to monitor creep as a function of time.

Characterization after creep testing typically included optical microscopy (OM) and scanning electron microscopy (SEM). At the test temperatures examined in this study, the fracture surfaces of silicon nitride specimens tend to quickly and heavily oxidize in the furnace after fracture and during cool down which hinders microstructural observation. Crept specimens were refractured at room temperature within the gage section to reveal a non-oxidized surface for SEM examination. In some instances, specimen cross-sections were polished to a $0.25 \mu \mathrm{m}$ finish to supplement the OM analysis.

Analytical electron microscopy (AEM) was used to observe the thin grain boundaries of one of the HIPed silicon nitrides, NCX-5102. In addition, the chemistry of the grain boundary phase was examined using energy dispersive spectroscopy (EDS). The objective of these analyses was to examine whether any structural or chemical changes or gradients occurred as a result of creep testing. For this study, any microstructural changes observed in crept NCX-5102 were taken to be representative of changes or trends in the other HIPed silicon nitrides which have also been creep tested (we expect to verify or disprove this assumption in future work). Consequently, discussion of the results obtained with NCX5102 are used somewhat interchangably with, and extended to, other HIPed silicon nitrides.

\section{RESULTS \& DISCUSSION}

Creep testing HIPed silicon nitride materials at relatively high temperatures and low tensile stresses results in the formation of macroscopically large damage zones or stress corrosion cracking (SCC) zones. Examples of these damage zones were observed on the original fracture surfaces of two NCX-5102 (4\% yttria as a sintering aid) specimens creep tested at $1370^{\circ} \mathrm{C}$ and $140 \mathrm{MPa}$ and are shown in Fig. 2. Specimens "1" and "2" in Fig. 2 had lifetimes of 44 and 132 hours, respectively, and their creep histories are shown in Fig. 3. Creep as a function of time exhibited a continuously decreasing creep rate to fracture and no tertiary creep was observed. In addition to NCX-5102, these similar damage zones have been observed on NT154, NT164, and PY6 HIPed silicon nitrides after failure due to 
creep rupture. These damage zones initiate at the specimen surface and the zones advance radially inwards. The shape of the crack may be described as a "circumferential surface crack", and the stress intensity of the crack type has been examined by Raju and Newman, $\mathrm{Jr}^{2}{ }^{2}$ The growth of a damage zone continues until the stress intensity associated with the crack size and tensile stress becomes critical, and the specimen fractures. The orientation of the hackle marks on the two specimen shown in Fig. 2 suggests that fracture was initiated at one corner of the SCC zone at the specimen's surface; this is consistent with all damage zones observed in creep ruptured NCX-5102, NT154, NT164, and PY6.

Figure 2. Examples of damage zones, or stress corrosion cracking zones, on fracture surfaces of HIPed silicon nitride (NCX-5102) specimens creep tested at $1370^{\circ} \mathrm{C}$. Specimens 1 and 2 are shown, with arrows indicating the thickness of the SCC zone.

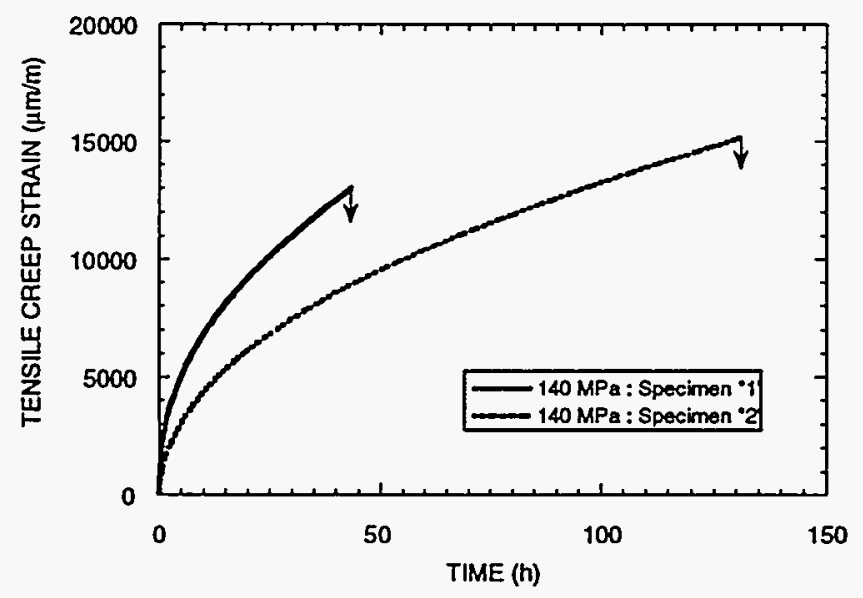

Figure 3. Examples of creep histories of NCX-5102, specimens 1 and 2 from Fig. 2.

Optical micrographs of polished specimen cross-sections of crept NCX-5102 silicon nitride are shown in Fig. 4. A color or shading gradient hundreds of microns thick is observed on both NCX-5102 specimen cross-sections; similar shading gradients have been observed in crept PY6, NT154, and NT164 silicon nitrides. Although the shading gradient provides no quantitative information, it does suggest that some microstructural changes have occurred during creep testing. The annular appearance of the shading, coupled with the cylindrical specimen geometry, suggests that some diffusional processes may have caused microstructural changes. Others have reported on similar shading gradients in silicon nitrides, ${ }^{3-5}$ but any correlation between cavitation and chemical gradients was not addressed. It is interesting to note that the total thickness of the outer annular rings is approximately the same as the distance advanced by the SCC zones in Fig. 2. Specimen "1" crept faster and had a shorter lifetime than specimen "2", as shown in Fig. 3. Although both specimens "1" and "2" were NCX-5102 silicon nitride, specimen "2" was subjected to an additional heat treatment process which resulted in a slower creep rate and longer lifetime. It is interesting to note that specimen " 1 " in Fig. 4 has a thicker ring than specimen "2"; this is the same specimen that had a faster creep rate and shorter lifetime too. This suggests that the faster mass transport of the chemical species and growth of the SCC zone in specimen "1" is affiliated with the faster creep and a shorter lifetime. 
Figure 4. Polished cross-sections show visible ring patterns on specimens "1" and "2" shown in Fig. 2 The total thickness of the annular shaded region, indicated by the arrows, is approximately the same as the thickness of the SCC zones shown in Fig. 2.

In order to determine the extent of the microstructural and property changes, Vickers microhardess measurements, $\mathrm{X}$-ray diffraction, AEM, and EDS analyses were performed as a function of radial position. The Vickers microhardness was found to be less in the shaded outer rings of both specimens shown in Fig. 4 , and the $\alpha / \beta$ phase ratio of silicon nitride was greater nearer the surface than that in the center of both specimens. ${ }^{6}$ The presence or absence of lenticular-shaped cavities was strongly dependent on radial position. Lenticular cavities were much more prevalent nearer the surface than they were in the center of the crept specimen, as shown in Fig. 5. Refracturing the crept specimen at room temperature revealed a microstructure having a dense, but small-sized, population of lenticular cavities at position "B" in Fig. 5. Lenticular cavities were also found at position "C", close to the specimen's surface, however their concentration appeared to be less, but their size was typically larger. Few lenticular cavities were observed in the center of the specimen. Triple point or multi-grain junction cavities appeared to be homogeneously distributed throughout the gage volume. The presence and volume fraction of lenticular cavities was found to be dependent on the radial position of crept NCX-5102, while that of multi-grain junction cavities was independent on the radial position.

Figure 5. Lack of lenticular cavities existed in the center of crept specimen "1" [location A], were very concentrated about $\approx 300 \mu \mathrm{m}$ from the specimen surface [location B], but were the largest near the specimen surface [location $C-\approx 50 \mu \mathrm{m}$ from the surface]. Locations $B$ and $C$ are within the outer shaded region of specimen "1" shown in Fig. 4.

In addition to the lenticular cavity dependence on radial position within the crept HIPed silicon nitride, AEM revealed positional dependence of a presence of deposited triple point grain boundary "pockets". To clarify terminology, various grain boundaries types are schematically depicted in Fig. 6. Two grain boundaries (2GB) and triple point grain boundaries (3GB) are conventional representations and are simply junctions separating two and three grains, respectively. The object of interest in Fig. 6 is the triple point grain boundary "pocket" (3GB-Pocket). A high magnification image of a 3GB-Pocket is shown in Fig. 7; it is a physical entity containing material and should not be misinterpreted as a void or cavity. During transmission electron microscopy, 3GB-Pockets were found to reside at triple point or multi-grain junction grain boundaries only, were amorphous, and had a size smaller than $10 \mathrm{~nm}$. Similarly to the presence of lenticular cavities, the 3GB-Pockets were highly concentrated within the outer volume of the crept specimen; this volume is the same as the lightly shaded region on the specimen cross-sections shown in Fig. 2. Within the center of the specimen, 3GB-Pockets were rarely observed.

Chemical analysis of the grain boundaries revealed interesting results. AEM foils were prepared from specimen " 1 " on longitudinal planes positioned at the three locations illustrated in Fig. 8. Analysis was done using a focused $2 \mathrm{~nm}$ electron probe. A high concentration of oxygen and yttrium were found in 3GBs near the specimen's surface; little, if any, of 
these two species were found in 3GBs in the center of the specimen. This evidence shows that yttrium and oxygen diffused towards the surface of the specimen, from the bulk, and accumulated near the surface. EDS analysis of 3GB-Pockets showed high concentrations of yttria and oxygen too, even moreso than in the $3 \mathrm{GBs}$ near the specimen's surface.

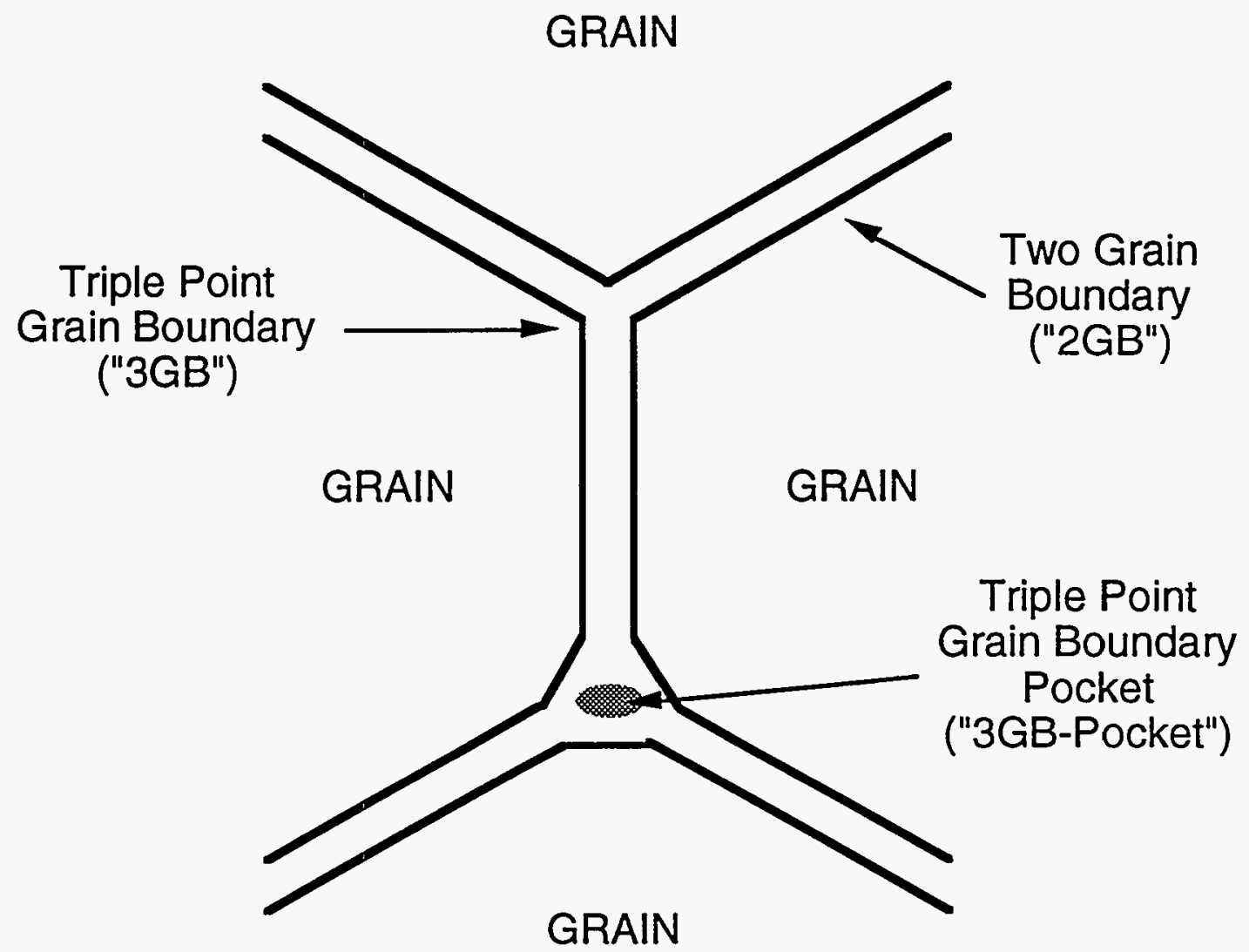

Figure 6. Schematic drawing showing the defined grain boundary regions for the TEM and its EDS analysis.

Figure 7. Example of a triple point grain boundary pocket observed in specimen "1". A high concentration of these pockets existed near the surface [locations B and C in Fig. 5], but were rarely observed in the center of the specimen.

Figure 8. EDS analysis showed that yttrium and oxygen gradients existed after creep testing in ambient air through the cross-section of the NCX-5102 specimen "1". Chemistry within a 3GB in the center of the specimen is compared with a 3GB and a 3GB-Pocket near the surface of crept specimen "1".

The positional dependence of the chemistry (higher concentrations of yttrium and oxygen nearer the specimen surface) and microstructure (concentrated lenticular cavities nearer the specimen surface) of crept NCX-5102 silicon nitride is believed to be associated with the formation of the damage zones or stress corrosion cracking zones shown in Fig. 2. The mass transport of oxygen and yttrium towards the specimen's surface is associated with 
the formation of densely populated lenticular cavities in the same vicinity (i.e., the corrosive mechanism of SCC). The viscosity of yttrium-aluminum-silicon oxynitride glasses has been shown to decrease as the ratio of oxygen to nitrogen increases. ${ }^{7}$ The EDS results show that the oxygen to nitrogen ratio is much higher near the surface of crept NCX-5102; therefore, the viscosity of the grain boundary phase in this vicinity may be lower and permits easier cavity nucleation and growth. Flaws present at the specimen surface (e.g., resulting from machining) are believed to nucleate the damage zone, although numerous searches have not yielded proof of this yet. The damage zone then advances via the coalescense of microcracks and cavities.

The proposed evolution of failure of HIPed silicon nitride materials at relatively high temperatures and low stresses is depicted in Fig. 9. A SCC front advances radially inwards as oxygen and yttrium migrate and accumulate near the specimen surface while oxygen diffuses into the specimen from the air environment. The migration of these species appears to provide favorable conditions for the nucleation and growth of lenticular cavities. A large damage zone or SCC zone advances with the stress corrosion front. The damage zone continues to grow in size during the creep test until its size becomes critical and fracture occurs. It is to the advantage of designers and manufacturers of AGT components made from HIPed silicon nitrides to acknowledge this mode of failure.

Figure 9. Schematic describing the evolution of failure from stress corrosion cracking.

\section{SUMMARY}

The damage mechanisms associated with oxidation and creep have been found to act concurrently. Energy dispersive spectroscopy has shown that atmospheric tensile creep testing of HIPed silicon nitride results in the creation of chemical gradients of oxygen and yttrium across the radial dimension of button-head specimens. At and near the surface of a crept specimen, higher concentrations of yttrium and oxygen were found to exist in amorphous "pockets", which were located within multi-grain junctions. The accumulation of oxygen and yttrium coincided with dense populations of lenticular-shaped cavities observed during fractography. The center of the crept specimen contained little or no oxygen or yttrium or amorphous pockets; in addition, lenticular cavities were rarely observed. The ambient environment appeared to provide a driving force at elevated temperatures for the accumulation of both cation and anion diffusion at the specimen's surface. The coincident gradient in lenticular-cavity concentration appears to be affiliated with this phenomenon.

A SCC zone forms in HIPed silicon nitride materials when subjected to high temperatures and stress in ambient air. The extent of this SCC zone increases if the temperature is higher and/or the stress is lower. Stress-corrosion cracking initiates at the surface of the tensile specimen and grows radially inwards. What actually initiates SCC has not yet been identified, but it is believed to result from a stress-concentrator (e.g., machining damage) at the specimen's surface and its growth results from the coalescence of microcracks and cavities. The degradation of the high temperature mechanical integrity within this volume of material near the specimen's surface is associated with the growth of a SCC zone. This stress-corrosion crack continues to grow in size during tensile loading until it reaches a critical size which causes fracture.

\section{ACKNOWLEDGMENTS}


The authors wish to thank Drs. K. Breder, H. Cai, and A. E. Pasto for reviewing the manuscript and for their helpful comments.

\section{REFERENCES}

1. A. A. Wereszczak, K. Breder, and M. K. Ferber, "Role of Oxidation in the TimeDependent Failure Behavior of Hot Isostatically Pressed Silicon Nitride at $1370^{\circ} \mathrm{C}$," Journal of the American Ceramic Society, 76 [11] 2919-22 (1993).

2. I. S. Raju and J. C. Newman, Jr., "Stress Intensity Factors for Circumferential Surface Cracks in Pipes and Rods Under Tension and Bending Loads," NASA Technical Memorandum, Report No. NASA TM-87594, 1985.

3. A. A. Wereszczak, T. P. Kirkland, K. Breder, M. K. Ferber, and P. Khandelwal, "High Temperature Dynamic Fatigue Performance of a Hot Isostatically Pressed Silicon Nitride," In press Materials Science and Engineering.

4. Y. G. Gogotsi and G. Grathwohl, "Stress-Enhanced Oxidation of Silicon Nitride Ceramics," Journal of the American Ceramic Society, 76 [12] 3093-104 (1993).

5. D. R. Clarke, "A Comparison of Reducing and Oxidizing Heat Treatments of HotPressed Silicon Nitride," Journal of the American Ceramic Society, 66 [2] 92-95 (1983).

6. A. A. Wereszczak, M. K. Ferber, and T. P. Kirkland, "Effects of Oxidation and Creep Damage Mechanisms on Creep Behavior in HIPed Silicon Nitrides," Ceramic Engineering and Science Proceedings, Pages, Vol. 15, No. 7-10, pp 49-56, 1994, 18th Annual Conference on Composites and Advanced Ceramics.

7. S. Hampshire, R. A. L. Drew, and K. H. Jack, "Viscosities, Glass Transition Temperatures, and Microhardness of $\mathrm{Y}$-Si-Al-O-N Glasses," Communications of the American Ceramic Society, 67 [3] C46-C47 (1984). 

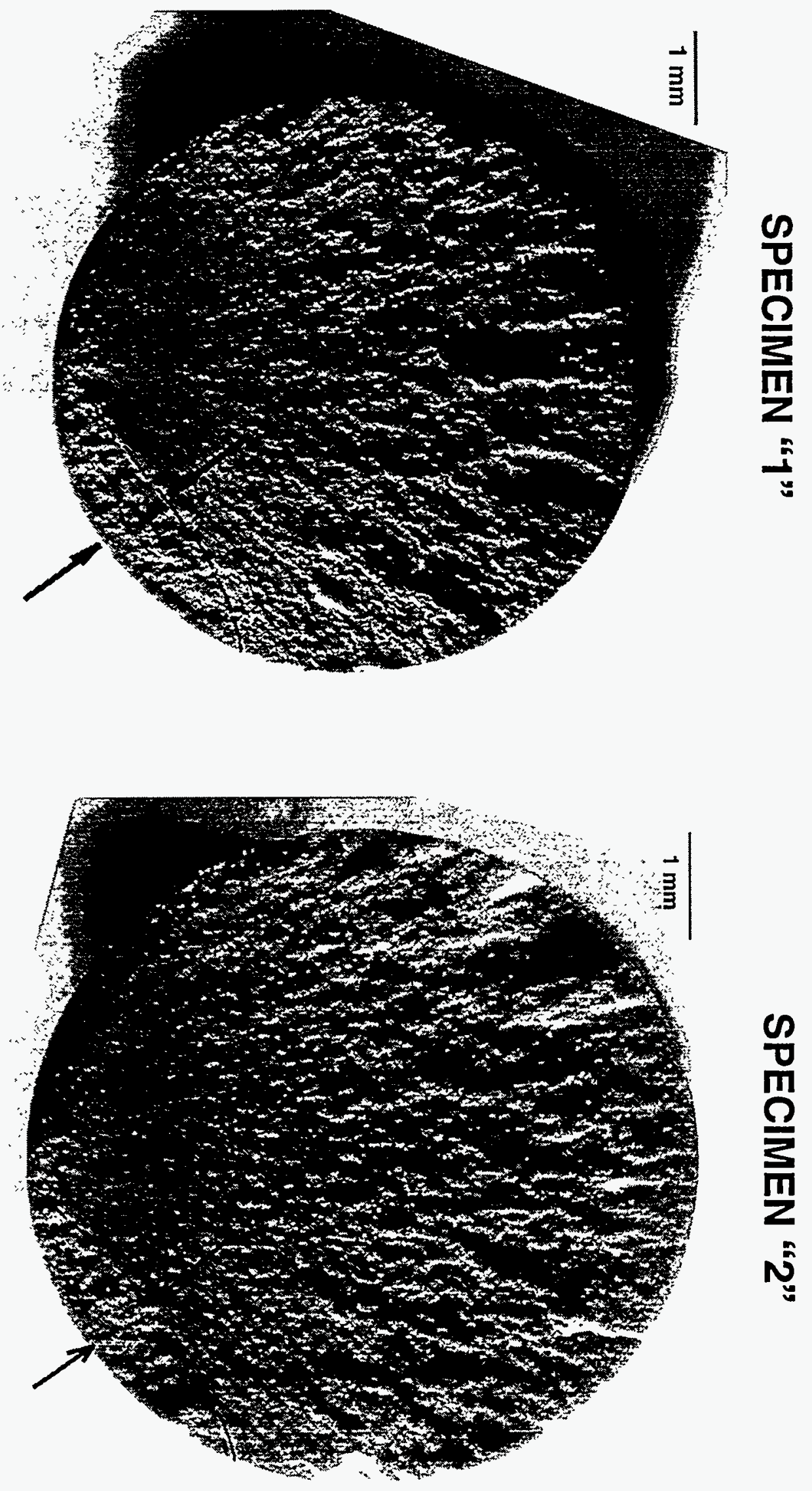

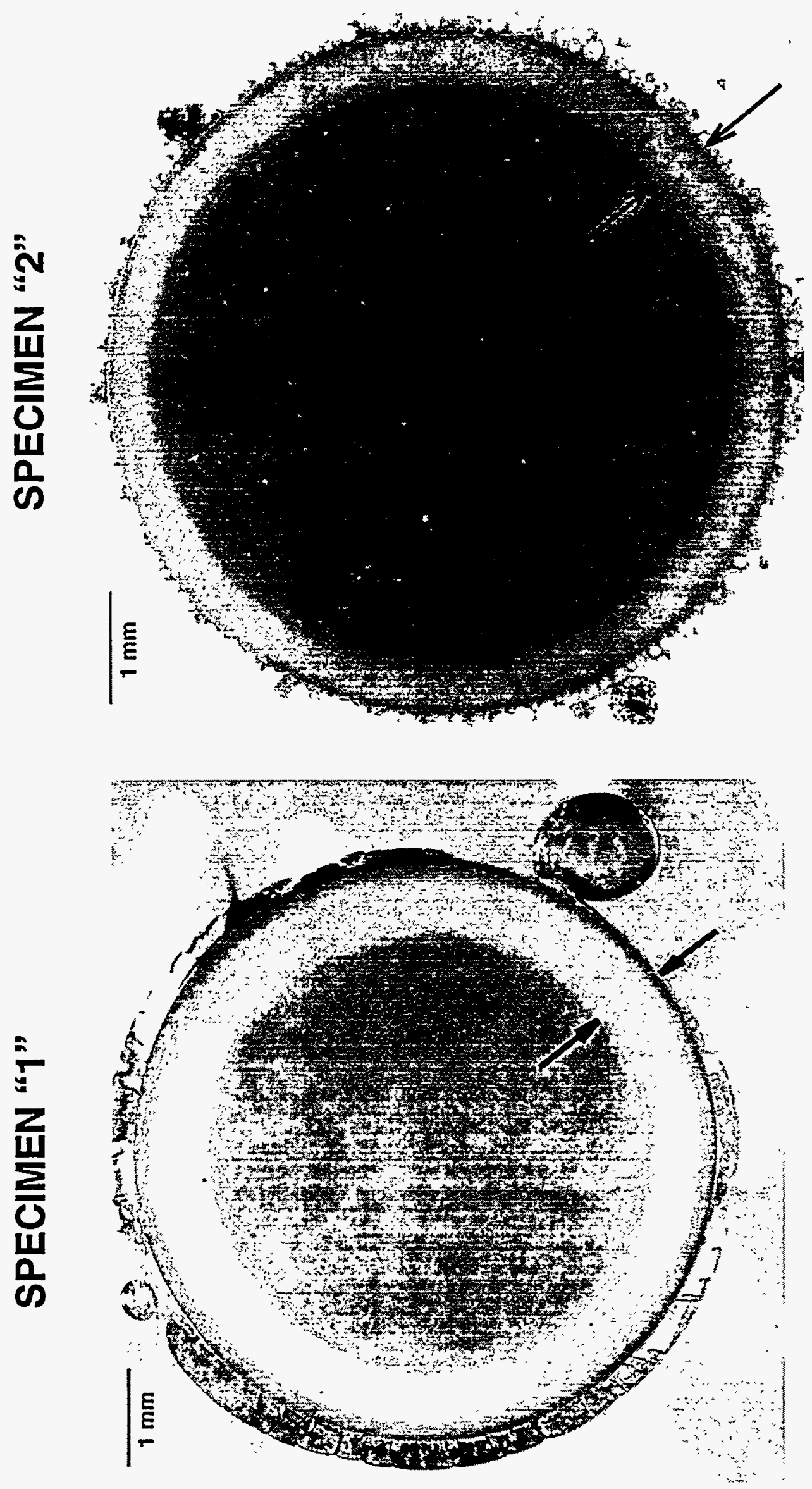


\section{TENSILE SPECIMEN CROSS-SECTION}

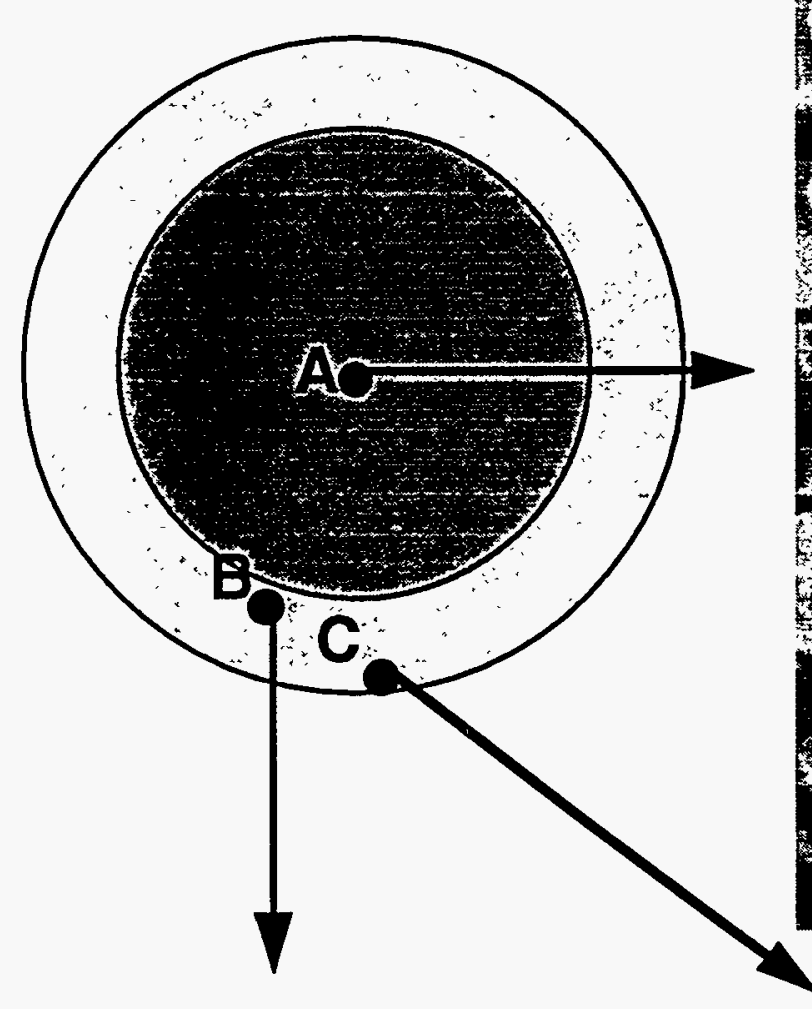

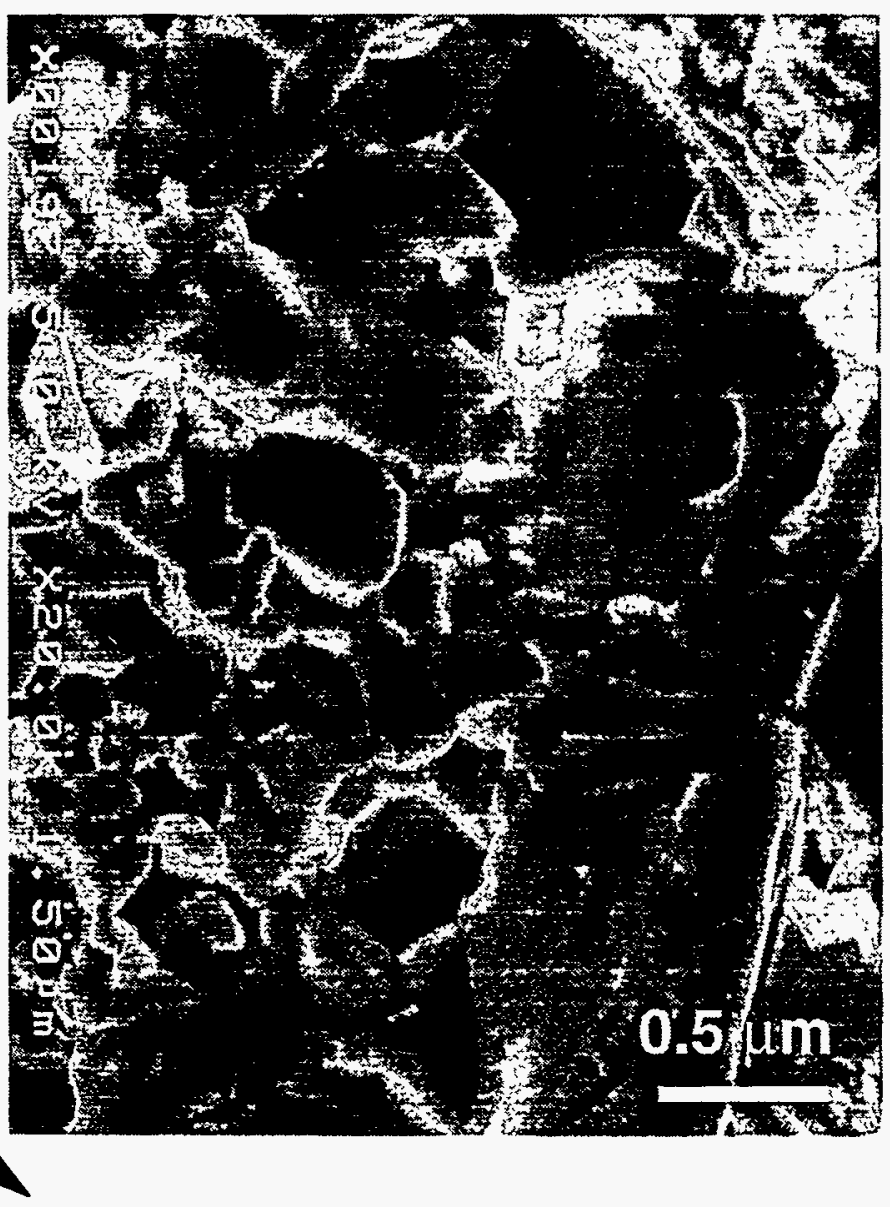

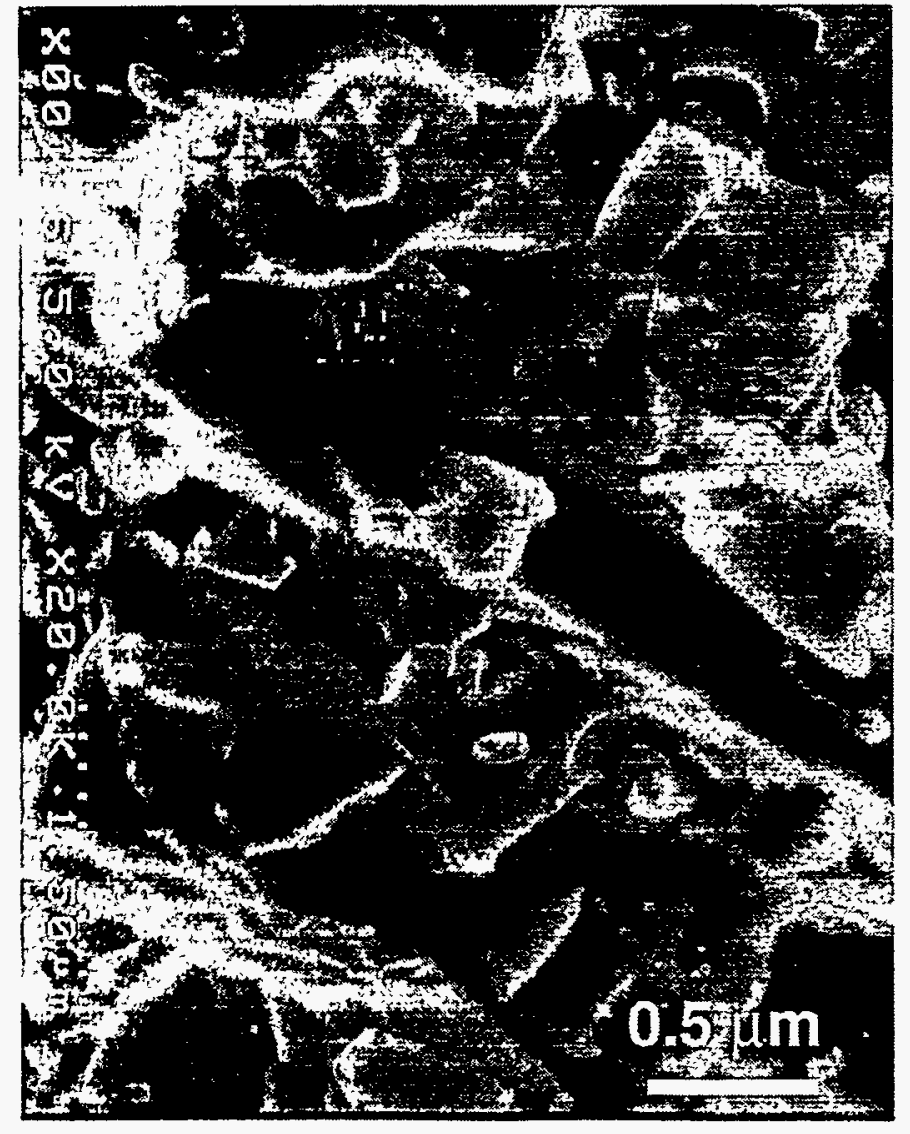

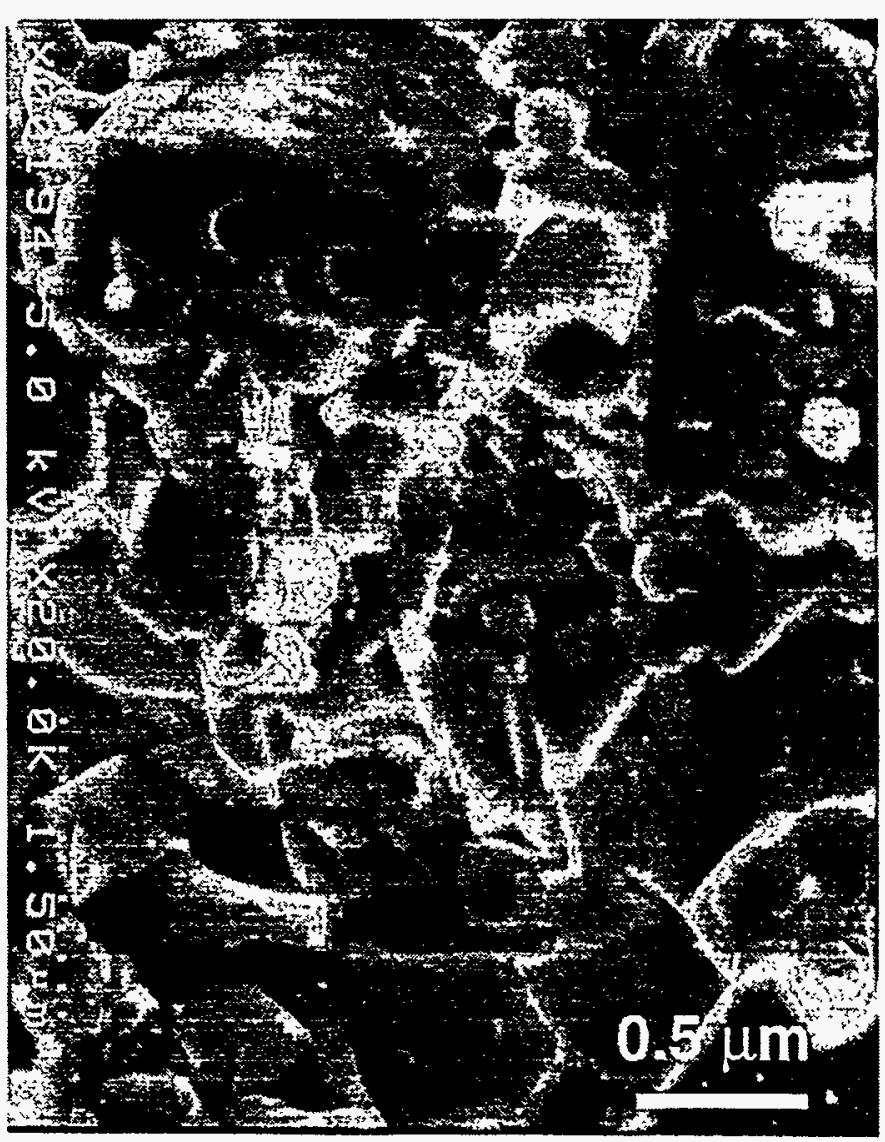




\section{$L \rightarrow I J$}

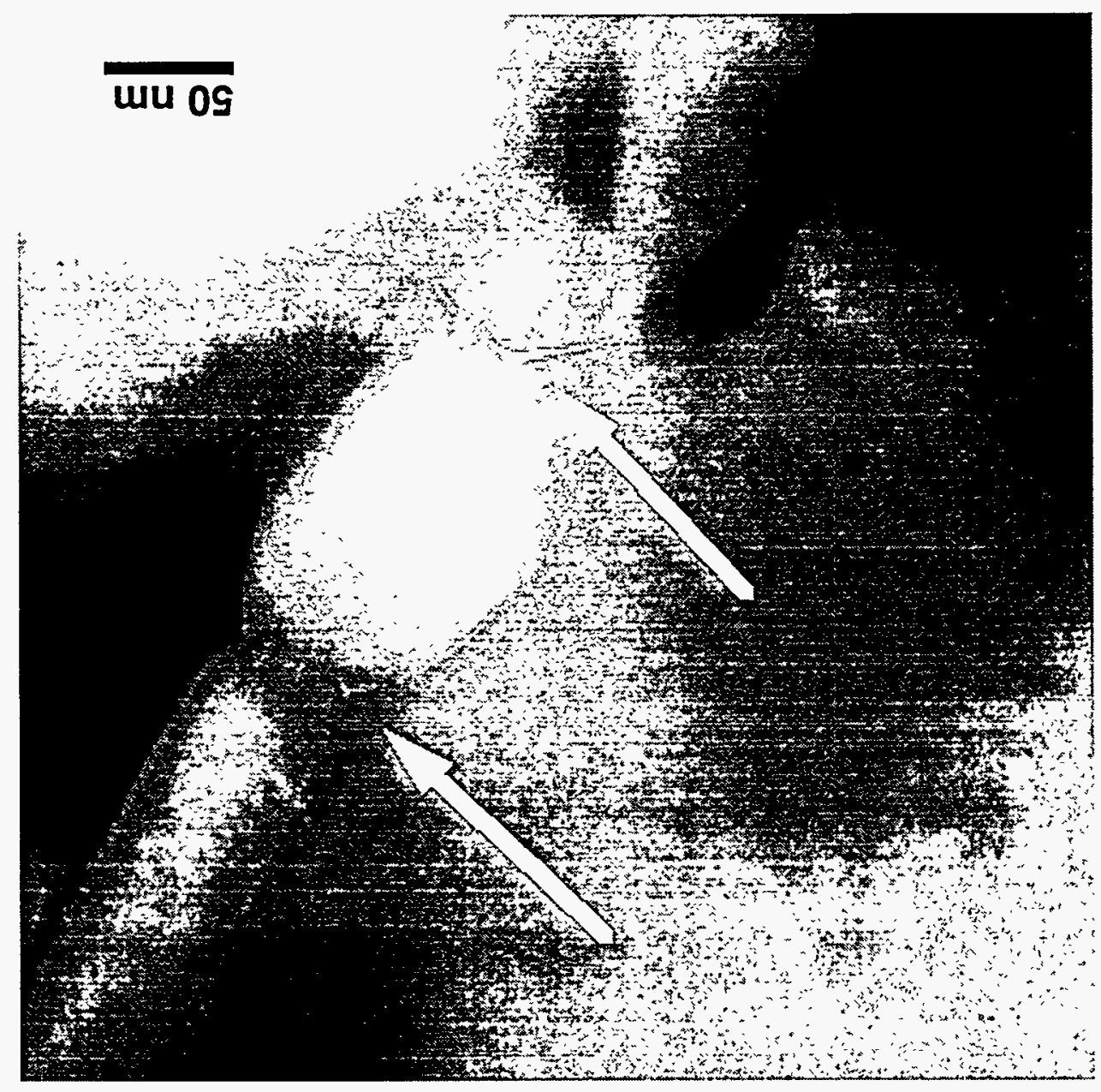



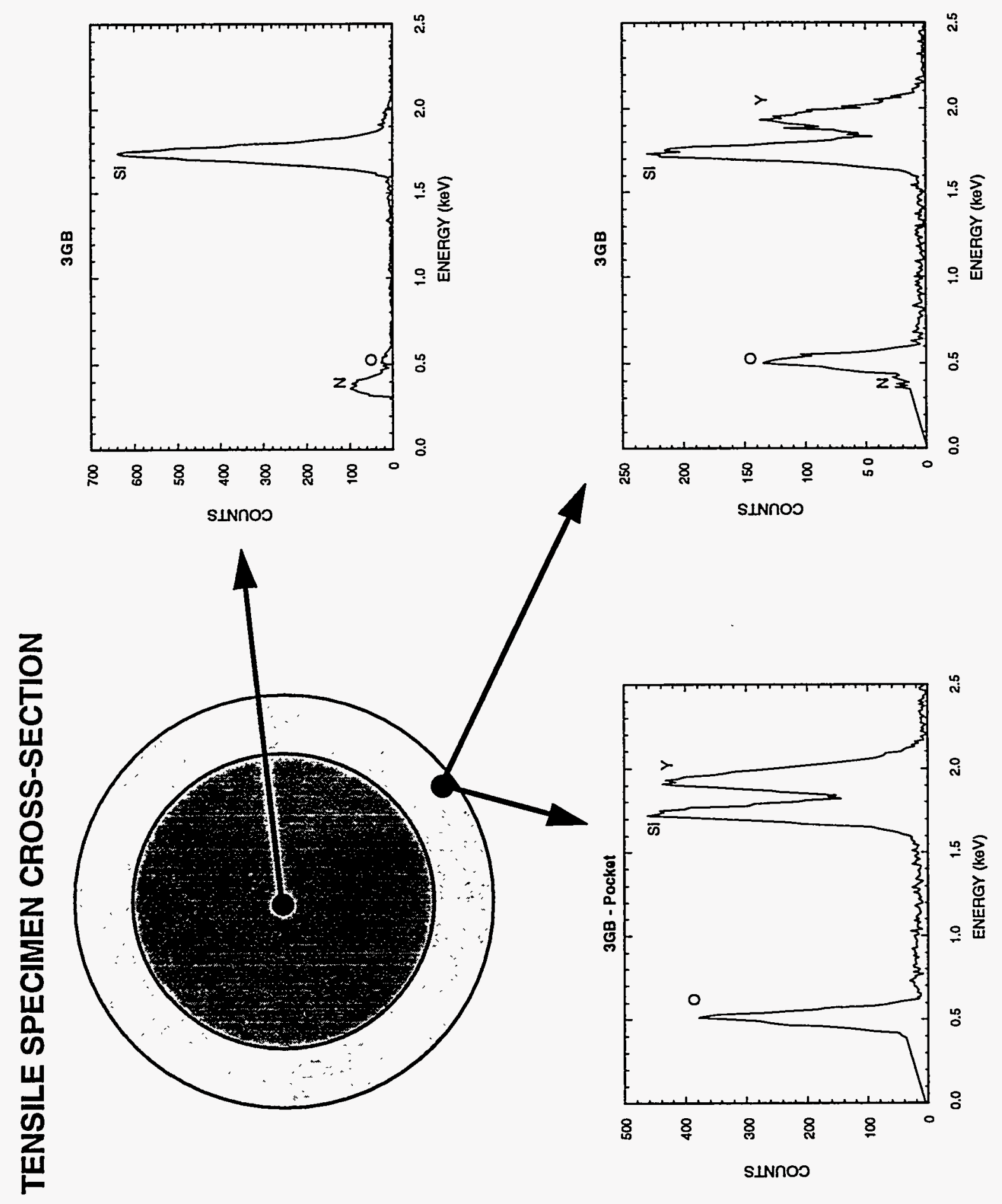

FIG 8 
Silicon nitride tensile specimen cross-section at an elevated temperature...

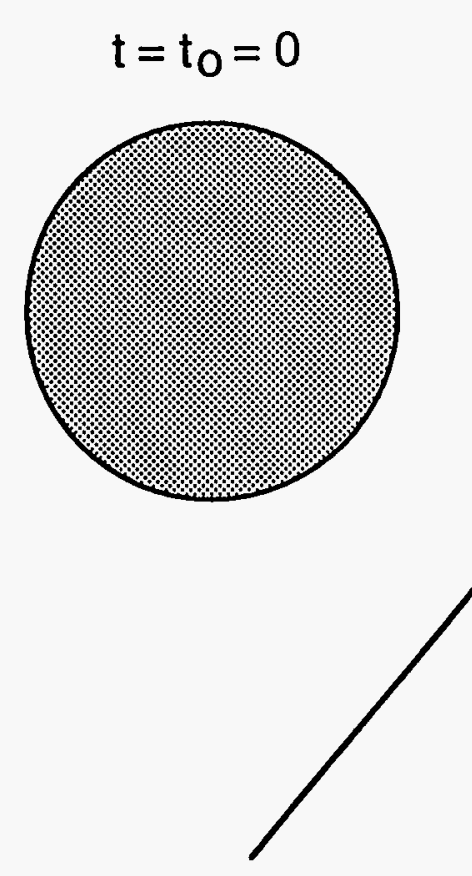

Stress corrosion front is activated and advances radially inwards as time progresses at high temperature

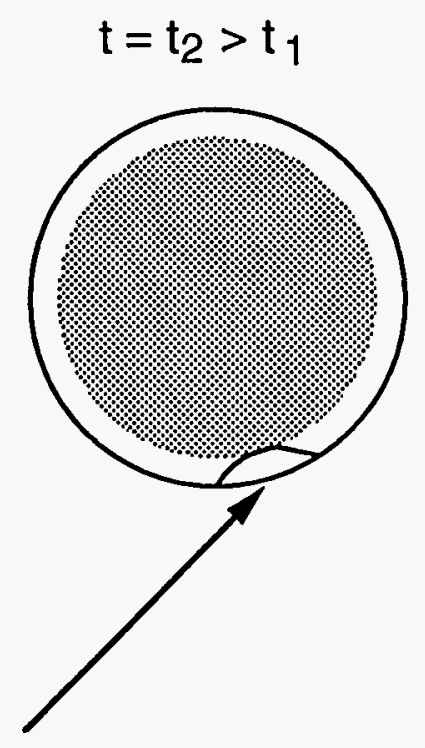

Microcrack coalescence or single macroscopic crack (i.e. the front of the stress corrosion cracking damage zone), coincident with extent of vitrification front, however it is not yet critical $\left(\mathrm{K}_{\mathrm{I}}<\right.$ material $\left.\mathrm{K}_{\mathrm{Ic}}\right)$

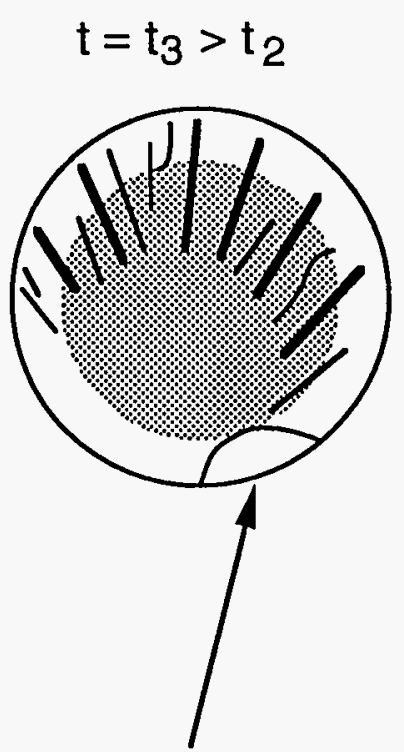

Stress corrosion cracking damage zone reaches a critical size and produces a stress failure, with mirror, mist, and hackle markings indicating that failure originated where one of its two corners intersect the specimen surface 